\title{
PENURUNAN WARNA LIMBAH CAIR INDUSTRI SARUNG SAMARINDA DENGAN KARBON AKTIF DARI BATUBARA KOTOR
}

\section{DESCREAMENT OF COLOUR CONTENT OF THE LIQUID WASTE PRODUCT FROM SARONG SAMARINDA INDUSTRIES BY ACTIVATED CARBON FROM DIRTY COAL}

\author{
Haspiadi \\ Balai Riset dan Standardisasi Industri Samarinda \\ Jalan Harmonika No. 3 Samarinda Telp. (0541) 732274, Fax (0541) 745431 \\ Email : haspiadi_k@yahoo.com
}

Naskah diterima 17 Januari 2012, disetujui 12 April 2012

\begin{abstract}
ABSTRAK
Salah satu dampak negatif dari industri sarung Samarinda adalah limbah cair yang berasal dari proses pencelupan dan pewarnaan. Oleh karena itu sebelum dibuang ke badan air perlu diolah terlebih dahulu. Penelitian ini dilakukan untuk mengolah limbah cair dengan karbon aktif sebagai adsorber yang dibuat dari batubara kotor. Proses adsorbsi dilakukan dengan menambahkan karbon aktif ke dalam limbah cair masingmasing dengan waktu kontak 10 menit, 20 menit dan 30 menit. Filtrat yang dihasilkan warnanya diukur menggunakan spektrofotometer UV-Vis pada panjang gelombang $355 \mathrm{~nm}$. Hasil penelitian menunjukkan bahwa dosis optimum dari karbon aktif yang digunakan adalah $0,5 \%$ dan waktu kontak 30 menit dapat menurunkan warna air limbah sebesar $98,42 \%$.
\end{abstract}

Kata Kunci : Batubara kotor, industri sarung Samarinda, karbon aktif, limbah cair, warna.

\begin{abstract}
One of the effects of Samarinda Sarong Industries is negative liquid waste from dying and coloring process. Therefore liquid waste must be treated before throwed away to water body. This research was done to treat liquid waste by activated carbon production from dirty coal as a adsorber. Adsorbtion was done by adding activated carbon to liquid waste during time contact 10 minuts, 20 minuts and 30 minuts. Filtrat was obtained measure by using UV-Vis spectrophotometer at the wave length of 355 $\mathrm{nm}$. The result of the experiment showed that dosage of activated carbon optimum in $0,5 \%$ and time contact 30 minuts can reduce $98,42 \%$ colour content of the liquid waste.
\end{abstract}

Keywords: Activated carbon, dirty coal, dying and coloring, liquid waste, Samarinda sarong industries

\section{PENDAHULUAN}

$\mathrm{P}$ erkembangan industri dan pola kehidupan masyarakat modern berhubungan langsung dengan peningkatan kebutuhan barang dan jasa, pemakaian sumber-sumber energi dan sumber daya alam. Pengunaan sumber daya alam secara besarbesaran dengan mengabaikan lingkungan mengakibatkan berbagai dampak negatif yang terasa dalam 
waktu yang relatif cepat maupun dalam jangka panjang.

Pada era pasar global dan pasar bebas sekarang ini, industri dihadap-kan pada persaingan yang ketat, sehingga keunggulan komparatif yang menjadi andalan pada masa lalu sudah tak mampu untuk menghadapi tantangan pasar bebas. Pem-bangunan pada satu sisi akan meningkatkan kualitas hidup manusia, yaitu peningkatan pendapatan masya-rakat, namun disisi lain menyebabkan penurunan kesehatan akibat adanya lingkungan yang rusak karena pencemaran .

Pencemaran diakibatkan oleh terbuangnnya limbah ke lingkungan. Limbah merupakan hasil yang tidak diinginkan dari kegiatan industri baik limbah cair, padat maupun gas. Oleh karena itu perlu penanganan yang serius dan terencana sehingga diharapkan tidak menimbulkan dampak lingkungan apapun bentuk-nya. Namun kenyataan saat ini di lapangan pengelolaan lingkungan masih sering mendapatkan porsi yang sangat kecil, akibatnya penanganan dan pengelolaan lingkungan menjadi tidak efektif.

Sebagai contoh air limbah yang dihasilkan dari suatu kegiatan yang dibuang langsung ke badan air baik sebelum maupun sesudah diolah tidak sedikit yang masih melampaui baku mutu yang dipersyaratkan. Salah satu penyebabnya adalah teknologi pengolahan air limbah yang diterapkan tidak sesuai dengan karakteristik air limbah yang diolah dan hanya menyesuaikan kondisi dan ketersediaan sarana di lapangan. Hal ini tidak hanya ditemukan di industri berskala kecil tetapi juga ditemukan di industri yang berskala menengah dan bahkan industri berskala besar.

Salah satu industri yang memiliki potensi terhadap pencemaran lingkungan adalah industri sarung Samarinda. Menurut data tahun 2010 saat ini jumlahnya mencapai 60 industri yang tersebar di sentra industri sarung Samarinda di Kecamatan Samarinda Seberang (Guntur, 2010). Dalam proses pe-warnaan benang menggunakan bahan pewarna reaktif yang dilarutkan dalam air. Dari proses ini dihasilkan sisa perendaman berupa limbah cair.

Limbah cair sisa perendaman benang walaupun volume dari sekali proses tidak banyak namun karena sifat warna air limbah yang sulit terpisah dan terurai, bila dibuang langsung ke badan air dapat menjadi ancaman bagi keselamatan ling-kungan sehingga perlu pengolahan yang serius agar tidak menimbulkan dampak negatif bagi lingkungan di sekitarnya. Oleh karena itu dalam penelitian ini dilakukan pengolahan dengan cara adsorpsi menggunakan karbon aktif yang dibuat dari batubara kotor sisa pengolahan batubara. Adsorpsi sendiri didefenisikan sebagai pengumpulan zat terlarut di permukaan media yang merupakan jenis adhesi yang terjadi pada saat padatan atau zat cair kontak dengan zat lainnya. Proses ini menghasilkan akumulasi konsentrasi zat tertentu di permukaan media setelah terjadi kontak antar muka atau bidang atas baik cairan, padatan maupun gas dalam waktu tertentu (Wigman. 1986). Sebagaimana tujuan dari penelitian ini untuk mengolah limbah cair sisa pewarnaan pada pembuatan sarung Samarinda secara adsorpsi dengan karbon aktif dari batubara kotor, diharapkan dapat menurunkan dampak negatif yaitu pencemaran yang ditimbulkan oleh sisa bahan perwarna.

\section{BAHAN DAN METODE}

\section{Bahan dan Alat}

Bahan yang digunakan dalam penelitian ini terdiri dari air limbah industri sarung Samarinda, batubara kotor (dirty coal), asam fosfat $\left(\mathrm{H}_{3} \mathrm{PO}_{4}\right)$, akuades, kertas $\mathrm{pH}$ (lakmus), kertas saring lembaran, serta bahan untuk pengujian sampel terdiri dari kobalt klorida anhidrous $\left(\mathrm{CoCl}_{2} \cdot 6 \mathrm{H}_{2} \mathrm{O}\right)$ dan kalium kloro platina $\left(\mathrm{K}_{2} \mathrm{PtCl}_{6}\right)$.

Sedangkan jenis peralatan yang digunakan terdiri dari crusher, ayakan 
$75 \mu \mathrm{m}$, blender, timbangan analitik, spektrofotometer UV-Vis, stop watch, labu ukur $100 \mathrm{~mL}$, gelas piala, spatula, ember, botol sampel dan tabung reaksi

\section{Metode Pembuatan Karbon Aktif}

Batubara kotor dikeringkan pada kondisi ruang, kemudian dicampur hingga homogen dan dihancurkan hingga diameter butiran lolos ayakan 75 um atau setara 245 mesh. Sampel yang telah siap di aktivasi secara kimia menggunakan asam fosfat $\left(\mathrm{H}_{3} \mathrm{PO}_{4}\right) 25$ $\%$ dan dikarbonisasi pada suhu $800^{\circ} \mathrm{C}$. Penetapan konsentrasi $25 \%$ dan suhu $800^{\circ} \mathrm{C}$ merupakan konsentrasi optimal dan suhu optimal hasil penelitian pendahuluan (Haspiadi. 2010).

\section{Pengolahan Air Limbah}

Air limbah yang digunakan diambil dari salah satu industri sarung Samarinda, selanjutya dianalisa zat warna menggunakan spektrofotometer UV-Vis pada panjang gelombang 355 $\mathrm{nm}$. Kemudian dilakukan pengolahan dengan cara menambahkan bubuk karbon aktif ke dalam air limbah atau disebut juga dengan powdered activated carbon treatment (PACT) dengan konsentrasi $0 \%$ (sebagai kontrol) $0,1 \%$, $0,2 \%, 0,3 \%, 0,4 \%, 0,5 \%, 0,6 \%, 0,7 \%$, $0,8 \%, 0,9 \%$ dan $1 \%$, waktu adsorbsi masing-masing 10 menit, 20 menit dan 30 menit dengan pengulangan sebanyak 3 kali.

\section{Rancangan Percobaan}

Hasil pengujian dianalisis menggunakan analisa sidik ragam untuk menguji pengaruh faktor perlakuan terhadap keragaman data. Kombinasi perlakuan adalah faktor persen penggunaan karbon aktif (A) dan faktor lama penyerapan (B). Adapun parameter uji yang termasuk dalam faktor pengujian adalah warna air limbah sebelum dan sesudah pengolahan mengacu SNI No 2413-1991, butir 3.2.4, Cara Uji Warna Air dan Air Limbah secara Spektrofotometri.

\section{HASIL DAN PEMBAHASAN}

Hasil uji penurunan warna limbah cair sarung Samarinda seperti pada Gambar 1.

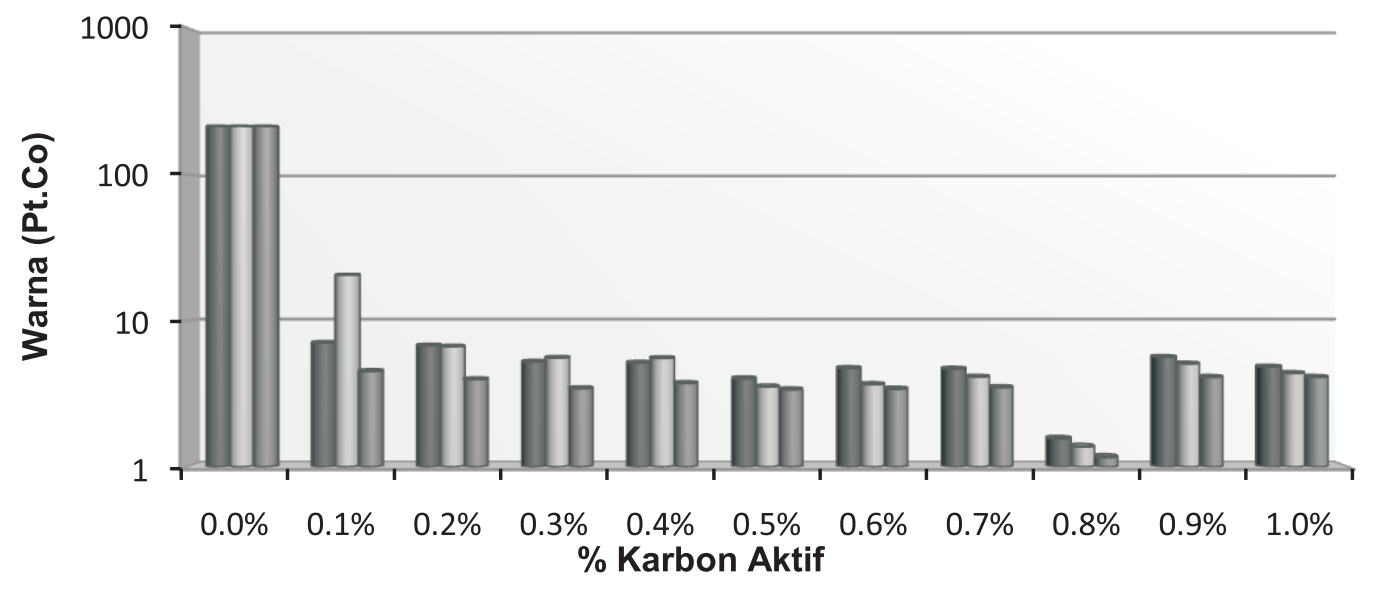

\begin{tabular}{c|c|c|c|c|c|c|c|c|c|c|c}
\cline { 2 - 10 } & $0.0 \%$ & $0.1 \%$ & $0.2 \%$ & $0.3 \%$ & $0.4 \%$ & $0.5 \%$ & $0.6 \%$ & $0.7 \%$ & $0.8 \%$ & $0.9 \%$ & $1.0 \%$ \\
\hline$\square 10$ menit & 214.38 & 7.12 & 6.80 & 5.27 & 5.19 & 4.05 & 4.76 & 4.71 & 1.57 & 5.68 & 4.88 \\
\hline$\square 20$ menit & 214.38 & 20.65 & 6.70 & 5.61 & 5.58 & 3.56 & 3.69 & 4.15 & 1.38 & 5.11 & 4.41 \\
\hline$\square 30$ menit & 214.38 & 4.54 & 3.99 & 3.46 & 3.76 & 3.40 & 3.43 & 3.52 & 1.17 & 4.14 & 4.14 \\
\hline
\end{tabular}

Gambar 1. Penurunan Warna Air Limbah Sarung Samarinda Sebelum dan Sesudah Pengolahan. 
Batubara kotor yang digunakan diaktifkan menggunakan asam fosfat dengan konsentrasi $25 \%$ dan dikarbonisasi pada suhu $800^{\circ} \mathrm{C}$ memiliki kemampuan daya serap tehadap iod sebesar 804,56 mg/g.

Hasil pengujian kandungan warna air limbah sarung Samarinda sebelum diolah sebesar 214,378 Pt.Co. Setelah dilakukan proses adsorpsi menggunakan karbon aktif dengan persentase bervariasi serta lama waktu penyerapan yang berbeda-beda menunjukkan penurun-an yang bervariasi. Parameter warna air limbah setelah diadsorpsi menggunakan karbon aktif $0,1 \%$ terjadi penurunan yang sangat besar untuk lama penyerapan 10 menit dihasilkan effisiensi penyerapan warna sebesar $96,68 \%$, namun untuk waktu 20 menit efektifitas penyerapan karbon aktif justru menurun dengan persen effisiensi sebesar $90,37 \%$. Penurunan efektifitas penyerapan karbon aktif dapat disebabkan oleh kejenuhan karbon aktif dalam menyerap warna air limbah. Kemudian untuk lama penyerapan 30 menit nilai warna air limbah menjadi 4,536 Pt.Co atau terjadi kenaikan efisiensi penyerapan warna sebesar $97,88 \%$.

Selanjutnya penggunaan karbon aktif $0.2 \%$ dengan lama penyerapan 10 menit terjadi penyerapan warna air dengan efisiensi $96,83 \%$, kemudian untuk lama penyerapan 20 menit efisiensi penyerapan sebesar $96,87 \%$ dan untuk lama penyerapan 30 menit efisiensi penurunan warna sebesar 98,14 atau mengalami kenaikan efisiensi dibandingkan dengan lama penyerapan 10 dan 20 menit untuk penggunaan karbon aktif $0,2 \%$. Kenaikan dapat disebabkan oleh waktu kontak antara karbon aktif dan limbah cair sehingga kemampuan menyerap menjadi optimal.

Penggunaan karbon aktif $0,3 \%$ warna air limbah menurun sebagaimana yang terjadi untuk penggunaan konsentrasi karbon aktif $0,1 \%$ dan $0,2 \%$. Efisiensi penurunan dengan lama penyerapan 10 menit sebesar $97,54 \%$, sedangkan lama penyerapan 20 menit sebesar $97,38 \%$ dan lama penyerapan 30 menit efisiensi sebesar 98,39\%. Kemudian dengan penggunaan karbon aktif $0,4 \%$ efisiensi penurunan hampir sama dengan persen penurunan sebesar $97,58 \%$ untuk lama penyerapan 10 menit, $97,40 \%$ untuk lama penyerapan 20 menit dan untuk lama penyerapan 30 menit efisiensi penyerapan sedikit lebih renda dari lama penyerapan 20 menit yaitu $98,25 \%$.

Hal yang sama untuk penggunaan karbon aktif $0,5 \%$, efisiensi penurunan zat warna dalam air limbah sarung Samarinda setelah diolah dengan cara adsorpsi, untuk lama penyerapan 10 menit sebesar $98,11 \%$ sedangkan untuk lama penyerapan efisiensi naik menjadi $98,34 \%$ dan demikian pula untuk lama penyerapan 30 menit efisiensi mengalami kenaikan sebesar $98,42 \%$.

Selanjutnya penggunaan karbon aktif $0,6 \%$ yang dibuat dari batubara kotor (dirty coal) untuk lama penyerapan 10 menit efisiensi penurunan sebesar $97,78 \%$, turun dibandingkan dengan efisiensi penyerapan dengan karbon aktif $0,5 \%$ walaupun kecil. Kemudian efisiensi naik kembali dengan lama penyerapan 20 menit sebesar 98,28\% dibandingkan efisiensi dengan lama penyerapan 10 menit. Demikian pula dengan lama penyerapan 30 menit ikut mengalami kenaikan sebesar $98,40 \%$.

Demikian pula dengan penggunaan karbon aktif $0,7 \%$ untuk menyerap zat warna air limbah kemampuan menyerap meningkat dengan indikasi persen penyerapan sebesar $97,80 \%$ untuk lama penyerapan 10 menit dan naik menjadi 98,06\% untuk lama penyerapan 20 menit, serta $98,36 \%$ untuk lama penyerapan 30 menit. Selanjutnya untuk penggunaan karbon aktif $0,8 \%$ efisiensi penurunan dengan lama penyerapan 10 menit sebesar $97,72 \%$ dan mengalami kenaikan dengan lama penyerapan 20 menit sebesar $97,99 \%$ dan lama penyerapan 30 menit efisiensi 
penurunan warna air limbah sebesar $98,16 \%$.

Untuk penggunaan karbon aktif $0,9 \%$ dengan lama penyerapan 10 menit efisiensi penurunan warna air limbah sarung Samarinda sebesar $97,35 \%$, dan dengan lama penyerapan 20 menit efisiensi penurunan sebesar $97,61 \%$ dan lama penyerapan 30 menit efisiensi penyerapan naik sebesar 98,07\%. Demikian pula dengan penggunaan $1 \%$ karbon aktif efisiensi penurunan warna air limbah untuk lama penyerapan 10 menit sebesar $97,73 \%$ kemudian lama peneyarapan 20 menit sebesar 97,94\% dan untuk lama penyerapan 30 menit efisiensi penurunan sebesar $98,07 \%$.

Efisiensi penurunan untuk semua perlakuan bervariasi dari penggunaan karbon aktif $0,1 \%, 0,2 \%, 0,3 \%, 0,4 \%$,
$0,5 \%, 0,6 \%, 0,7 \%, 0,8 \%, 0,9 \%$ dan $1 \%$ seperti pada Gambar 2. Nilai pengukuran warna air limbah awal sebelum diolah sebesar 214,378 Pt.Co, dengan penambahan $0,1 \%$ saja terjadi penurunan yang sangat drastis menjadi 7,116 Pt.Co atau efisiensi 96,68\% hanya dengan lama penyerapan 10 menit. Demikina pula untuk penggunaan karbon aktif hingga 1\% dengan lama penyerapan 10 menit, 20 menit dan 30 menit. Efisiensi yang cukup tinggi ini dapat dimungkinkan oleh bentuk karbon aktif bubuk yang digunakan sebagaimana dijelaskan oleh Miller (2000) bahwa jenis karbon aktif yang terbaik untuk menyerap warna adalah karbon aktif berbentuk bubuk sedangkan untuk menyerap gas berbentuk granular.

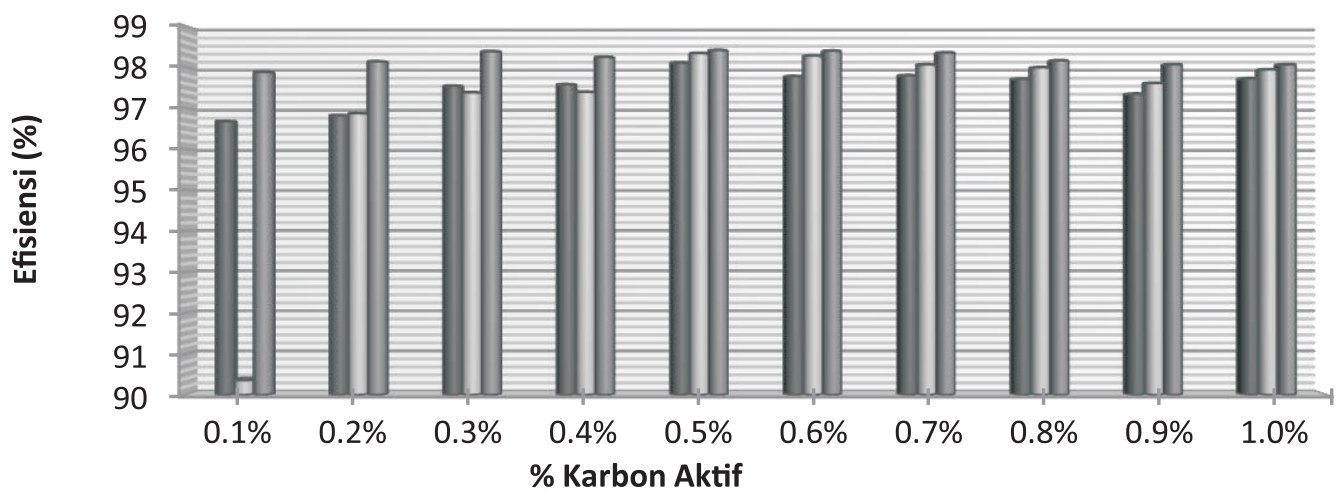

\begin{tabular}{c|c|c|c|c|c|c|c|c|c|c}
\cline { 2 - 10 } & $0.1 \%$ & $0.2 \%$ & $0.3 \%$ & $0.4 \%$ & $0.5 \%$ & $0.6 \%$ & $0.7 \%$ & $0.8 \%$ & $0.9 \%$ & $1.0 \%$ \\
\hline$\square 10$ menit & 96.68 & 96.83 & 97.54 & 97.58 & 98.11 & 97.78 & 97.80 & 97.72 & 97.35 & 97.73 \\
\hline$\square 20$ menit & 90.37 & 96.87 & 97.38 & 97.40 & 98.34 & 98.28 & 98.06 & 97.99 & 97.61 & 97.94 \\
\hline$\square 30$ menit & 97.88 & 98.14 & 98.39 & 98.25 & 98.42 & 98.40 & 98.36 & 98.16 & 98.07 & 98.07 \\
\hline
\end{tabular}

Gambar 2. Grafik Efisiensi Penurunan Warna Air Limbah Sarung Samarinda

Hasil perhitungan statistik dengan analisa sidik ragam pengaruh penggunaan karbon aktif dengan lama penyerapan menunjukkan hasil untuk kombinasi perlakuan antara jumlah karbon aktif dan lama penyerapan menunjukkan pengaruh nyata yang dinotasikan dengan $\left({ }^{*}\right)$ dan nilai $F_{\text {hit }}>$ $\mathrm{F}_{\text {tab }}$ baik taraf $5 \%(2,03>1,68)$ maupun $1 \%(2,03>1,98)$. Demikian pula dengan interaksi kedua perlakuan menunjukkan pengaruh nyata dengan nilai $\mathrm{F}_{\text {hit }}>\mathrm{F}_{\text {tab }}$ baik taraf $5 \%(2,42>1,73)$ maupun $1 \%$ $(2,42>2,18)$.

Dari hasil perhitungan uji $F$ yang ditunjukkan pula dengan grafik bar pada Gambar 2, efisiensi penurunan yang tertinggi dalam penelitian ini dihasilkan dari kombinasi perlakukan penggunaan karbon aktif $0,5 \%$ dengan lama penyerapan 30 menit dengan rata-rata efisiensi sebesar $98,42 \%$. Nilai ini di 
atas dari perlakuan penggunaan karbon aktif dengan persentase lainnya dan lama penyerapan 10 dan 20 menit.

Lama penyerapan dari karbon aktif sangat berpengaruh terhadap efisiensi sebagaimana dijelaskan oleh Sembiring (2003) bahwa bila arang aktif ditambahkan dalam suatu cairan, dibutuhkan waktu untuk mencapai kesetimbangan. Selain ditentukan oleh dosis arang aktif, pengadukan juga mempengaruhi waktu singgung antara absorber dengan bahan terabsorbsi. Pengadukan dimaksud-kan untuk memberi kesempatan pada partikel arang aktif untuk ber-singgungan dengan senyawa serapan. Untuk larutan yang mempunyai viskositas tinggi, dibutuhkan waktu singgung yang lebih lama (Sembiring, 2003).

\section{KESIMPULAN}

Dari hasil penelitian yang telah dilakukan dapat disimpulkan bahwa karbon aktif yang dibuat dari batubara kotor (dirty coal) efektif menurunkan warna limbah cair sisa pewarnaan pada industri sarung Samarinda. Dari beberapa perlakuan diperoleh bahwa persentase penggunaan karbon aktif untuk menyerap warna yang optimum adalah $0,5 \%$ dan lama penyerapan 30 menit dapat menurunkan kandungan warna sebesar $98,42 \%$.

\section{SARAN}

Penggunaan karbon aktif yang ukuran diameternya kecil disarankan untuk dilakukan pengadukan agar kontak antara penyerap dan limbah cair sisa pewarnaan akan semakin besar dan efektifitas penyerapan semakin tinggi.

\section{DAFTAR PUSTAKA}

Haspiadi 2010. Pemanfaatan Batubara Kotor (Dirty Coal) Menjadi Karbon Aktif. Jurnal Riset Teknologi Industri, vol. 4 No. 7, Juni 2010

Hassler, S.J.W. 1974. Purification with Activated Carbon Industrial, Commercial Environmental, Chemical Publishing. New York.

Heaton, Alan. 1994. The Chemical Industry, second edition. Balckie Academic and Profesional Chapman \& Hal London.

Manurung. R dan Hasibuan. R. 2004. Perombakan Zat Warna Azo Reaktif Secara Anaerob-Aerob. Fakultas

Miller, T.L. 2004. The Extentions Toxicology Network. Extoxnet@ace.orst.edu. Diakses tanggal 14 April 2011.

Ningrum S.N 1976. Laporan Sementara Percobaan Pembuatan Karbon Aktif dari Batubara Rembang. Pusat Penelitian dan PengembanganTeknologi Miniral, Bandung

Ningrum. S.N 2000. Penelitian Kemungkinan Pemanfaatan Batubara Sumatera Selatan sebagai Karbon/Arang Aktif. Pusat Penelitian dan PengembanganTeknologi Mineral, Bandung.

Sembiring M.T dan Sinaga. T.S. 2003. Karbon Aktif

Smisek. M. and Cherny S. 1970. Activated Carbon Manufacture, Propersties and Applications. Elsevior Publishing Company.

Suprapto S. 2008. Karbon Aktif "Ensiklopedia Batubara"

Wigman. T. 1986. Fundamentals and Parctica Implications of Activated Carbon Production by Partial Gasifications of Carbonaceous Materials. In Figeirido J.L and Moulijn J.A (Eds) Carbon and Coal Gassification Martinus Nijhoff Publishers, Boston. Pp. 559-5599 